\title{
Surgical therapies for corneal perforations: 10 years of cases in a tertiary referral hospital
}

This article was published in the following Dove Press journal:

Clinical Ophthalmology

29 October 2014

Number of times this article has been viewed

\section{Hideaki Yokogawa \\ Akira Kobayashi \\ Natsuko Yamazaki \\ Toshinori Masaki \\ Kazuhisa Sugiyama}

Department of Ophthalmology, Kanazawa University Graduate School of Medical Science, Kanazawa, Japan
Correspondence: Hideaki Yokogawa Department of Ophthalmology, Kanazawa University Graduate School of Medical Science, I3-I Takara-machi, Kanazawa-shi, Ishikawa-ken 920-864I, Japan

Tel +81762652403

Fax+8I 762229660

Email hyoko@med.kanazawa-u.ac.jp
Purpose: To report surgical therapies for corneal perforations in a tertiary referral hospital. Methods: Thirty-one eyes of 31 patients (aged 62.4 \pm 18.3 years) with surgically treated corneal perforations from January 2002 to July 2013 were included in this study. Demographic data such as cause of corneal perforation, surgical procedures, and visual outcomes were retrospectively analyzed.

Results: The causes of corneal perforation $(n=31)$ were divided into infectious $(n=8,26 \%)$ and noninfectious ( $\mathrm{n}=23,74 \%$ ) categories. Infectious causes included fungal ulcer, herpetic stromal necrotizing keratitis, and bacterial ulcer. The causes of noninfectious keratopathy included corneal melting after removal of a metal foreign body, severe dry eye, lagophthalmos, canaliculitis, the oral anticancer drug S-1, keratoconus, rheumatoid arthritis, neurotrophic ulcer, atopic keratoconjunctivitis, and unknown causes. Initial surgical procedures included central large corneal graft $(n=17)$, small corneal graft $(n=7)$, and amniotic membrane transplantation $(n=7)$. In two cases the perforation could not be sealed during the first surgical treatment and required subsequent procedures. All infectious keratitis required central large penetrating keratoplasty to obtain anatomical cure. In contrast, several surgical options were used for the treatment of noninfectious keratitis. After surgical treatment, anatomical cure was obtained in all cases. Mean postoperative best corrected visual acuity was better at 6 months (logMAR 1.3) than preoperatively (logMAR 1.8$)$.

Conclusion: Surgical therapies for corneal perforations in our hospital included central large lamellar/penetrating keratoplasty, small peripheral patch graft, and amniotic membrane transplantation. All treatments were effective. Corneal perforation due to the oral anticancer drug S-1 is newly reported.

Keywords: corneal perforation, keratoplasty, amniotic membrane transplantation

\section{Introduction}

Corneal perforation is an emergent condition caused by various types of infectious and noninfectious corneal disorders. Surgical and/or nonsurgical intervention is sometimes required to close the perforation, to reform the collapsed anterior chamber, and to restore visual function. In the worst scenario, irreversible angle-closure glaucoma and microbial endophthalmitis can occur, which lead to blindness. ${ }^{1}$

There are a variety of approaches for the management of corneal perforations, from nonsurgical treatments such as bandage soft contact lenses and tissue glues, ${ }^{2}$ to surgical modalities such as simple cornea suturing, conjunctival flaps, multilayered amniotic membrane transplantation (AMT), ${ }^{3,4}$ and tectonic corneal grafts. ${ }^{5-8}$ The choice of the treatment depends on the size and location of the perforation and status of underlying diseases.

In the current study, we report the clinical results of surgical therapies for corneal perforations during the past decade in a tertiary referral hospital, Kanazawa University Hospital, Ishikawa, Japan. 


\section{Patients and methods}

This retrospective study was approved by the Ethical Committee of Kanazawa University Graduate School of Medical Science and followed the tenets of the Declaration of Helsinki. Thirty-one eyes of 31 consecutive patients ( $18 \mathrm{men}$, 13 women; mean age, $62.4 \pm 18.3$ years) with surgically treated corneal perforations of various types over a 10 -year period from January 2002 to July 2013 at Kanazawa University Hospital were included in this study. Small pinpoint perforations that were successfully cured by nonsurgical procedures such as bandage soft contact lens and corneal gluing were excluded from this study. Also, cases with traumatic globe rupture and laceration were excluded because traumatic ruptured and lacerated wounds are generally managed with primary suturing without filling material. Demographic data such as causes of corneal perforation, types of surgical procedures, anatomic cure rates, and visual outcomes were retrospectively analyzed. The infective organisms were confirmed by culture or histology of the resected specimen obtained during repair surgery. Anatomic cure was determined by stabile anatomic integrity of the eye, such as no leakage of aqueous humor, and resolution of the original cause of the corneal perforation. All data analysis was performed using Microsoft Office Excel 2007 software (Microsoft Corporation, Redmond, WA, USA), and $P$-values of less than 0.05 were considered to be statistically significant. The lower visual acuity was calculated as follows: ${ }^{9,10}$ light perception = $\log$ MAR 2.8, hand motions $=\log$ MAR 2.3, and counting fingers $=\log$ MAR 2.0 .

\section{Results}

The causes of corneal perforation $(n=31)$ were divided into two categories: infectious $(\mathrm{n}=8,26 \%)$ and noninfectious $(\mathrm{n}=23$, $74 \%$ ) (Table 1). The causes of corneal infection included fungal ulcer (Candida) $(\mathrm{n}=4)$, herpetic stromal necrotizing keratitis ( $\mathrm{n}=3$ ), and bacterial ulcer (Pseudomonas aeruginosa suspect) $(\mathrm{n}=1)$. The causes of noninfectious keratopathy included corneal melting after removal of a metal foreign body $(n=5)$, severe dry eye $(n=3)$, lagophthalmos $(n=3)$, canaliculitis $(n=2)$, the oral anticancer drug $\mathrm{S}-1(\mathrm{n}=1)$, keratoconus $(\mathrm{n}=1)$, rheumatoid arthritis $(n=1)$, neurotrophic ulcer $(n=1)$, atopic keratoconjunctivitis $(n=1)$, and unknown causes $(n=5)$.

As summarized in Table 2, initial surgical procedures included central large corneal lamellar/penetrating graft (Figures 1 and 2) (7.0-8.5 $\mathrm{mm}$ in diameter, $\mathrm{n}=17)$, small corneal patch graft (Figure 3) (4.0-6.5 mm in diameter, $\mathrm{n}=7$ ), and multilayered AMT (Figure 4) $(\mathrm{n}=7)$. Two cases failed after the initial surgery: an 81-year-old woman with fungal
Table I Causes of corneal perforation

\begin{tabular}{llll}
\hline Causes & & $\begin{array}{l}\text { Number of } \\
\text { patients }\end{array}$ & $\%$ \\
\hline Infectious & Fungal ulcer (Candida) & 4 & 13 \\
keratopathy & Herpetic stromal necrotizing & 3 & 10 \\
& keratitis & & \\
& Bacterial ulcer (Pseudomonas & I & 3 \\
& aeruginosa suspect) & & \\
& $\quad$ Total & 8 & 26 \\
Noninfectious & Corneal melting after removal & 5 & 16 \\
keratopathy & of a foreign body & & \\
& Severe dry eye & 3 & 10 \\
& Lagophthalmos & 3 & 10 \\
& Canaliculitis & 2 & 6 \\
& Oral anticancer drug, S-I & I & 3 \\
& Keratoconus & I & 3 \\
& Rheumatoid arthritis & I & 3 \\
& Neurotrophic ulcer & I & 3 \\
& Atopic keratoconjunctivitis & I & 3 \\
& Unknown & 5 & 16 \\
& Total & 23 & 74 \\
& & 31 & 100 \\
\hline
\end{tabular}

ulcer and a 46-year-old man with paracentral corneal perforation after iron metal removal. The first case was initially treated by small patch graft with incomplete resection of fungal lesion, and fungal infection recurred after 1 month. The patient was finally cured by secondary central large corneal graft. The second case was initially treated with multilayered AMT but closure of the perforation was incomplete, and the iris herniation worsened. The condition was finally cured by secondary small patch graft after 1 month. All infectious keratitis required central large penetrating keratoplasty. In contrast, noninfectious keratopathies were cured by several different surgical approaches.

Table 2 Initial surgical procedures

\begin{tabular}{llll}
\hline Procedures & & $\begin{array}{l}\text { Number of } \\
\text { patients }\end{array}$ & $\begin{array}{l}\text { Infectious: } \\
\text { noninfectious }\end{array}$ \\
\hline $\begin{array}{l}\text { Corneal } \\
\text { transplant }\end{array}$ & $\begin{array}{l}\text { Central large corneal } \\
\text { graft (7.0-8.5 mm in } \\
\text { diameter; penetrating } \\
\text { or lamellar) }\end{array}$ & 17 & $7: 10$ \\
& $\begin{array}{l}\text { Small corneal graft } \\
(4.0-6.5 \mathrm{~mm} \text { in diameter; }\end{array}$ & $7^{*}$ & $1: 6$ \\
& $\begin{array}{l}\text { penetrating or lamellar) } \\
\text { Total }\end{array}$ & 24 & $8: 16$ \\
& & $7^{*}$ & $0: 7$ \\
$\begin{array}{l}\text { Amniotic } \\
\text { membrane }\end{array}$ & & & \\
transplant & & & \\
\hline
\end{tabular}

Note: *Two cases required subsequent procedures (a central large graft for a failed small corneal graft, a small corneal graft for a failed amniotic membrane transplant). 

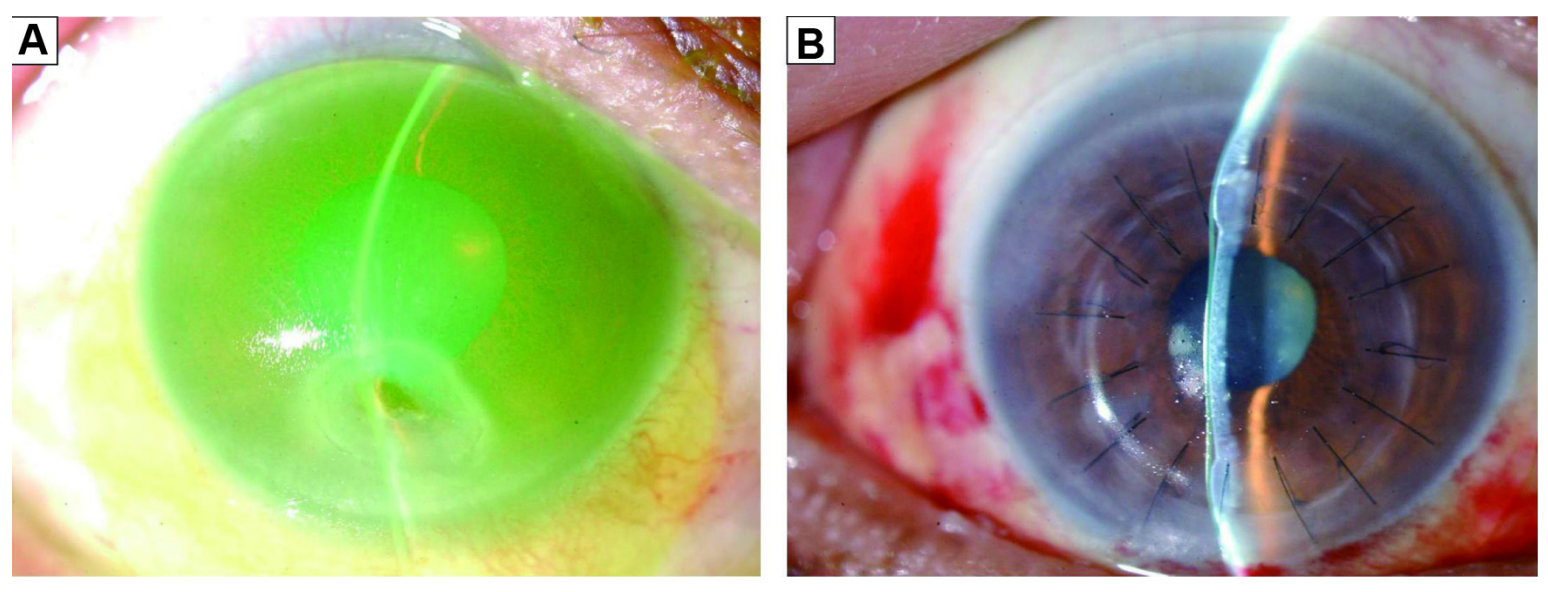

Figure I Representative slit-lamp biomicroscopic photograph of a noninfectious corneal perforation treated by a central penetrating large graft.

Notes: (A) A 74-year-old man with a paracentral corneal perforation due to the anticancer drug S-I (TS-I capsule, $100 \mathrm{mg} / \mathrm{day}$, Taiho Pharma, Tokyo, Japan). The iris prolapse in the lower paracentral cornea and the shallow anterior chamber with bandage soft contact lens (stained by fluorescein) are shown. (B) Two weeks after penetrating keratoplasty, the anterior chamber was re-formed.
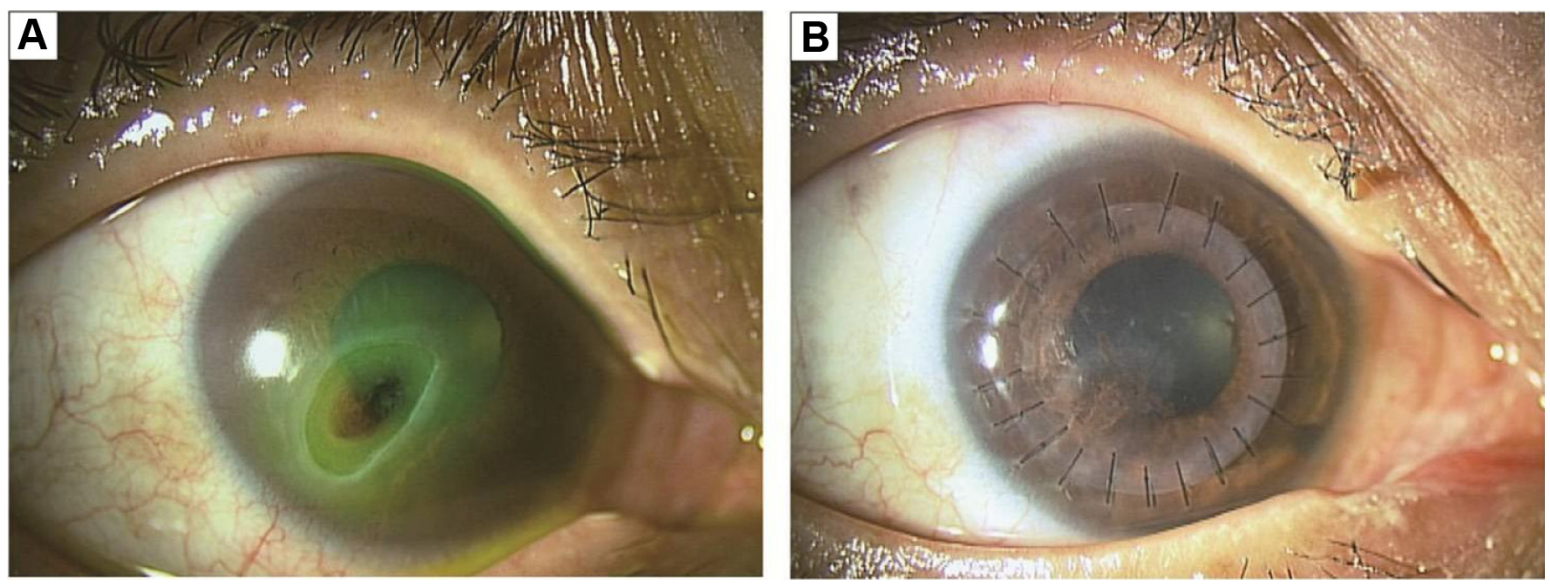

Figure 2 Representative slit-lamp biomicroscopic photograph of a noninfectious corneal perforation treated by a central lamellar large graft.

Notes: (A) A 47-year-old woman with a corneal perforation associated with a neurotrophic ulcer due to trigeminal nerve palsy with brain tumor. A large paracentral corneal perforation and shallow anterior chamber are shown. (B) Three months after anterior lamellar keratoplasty, the anterior chamber was re-formed.
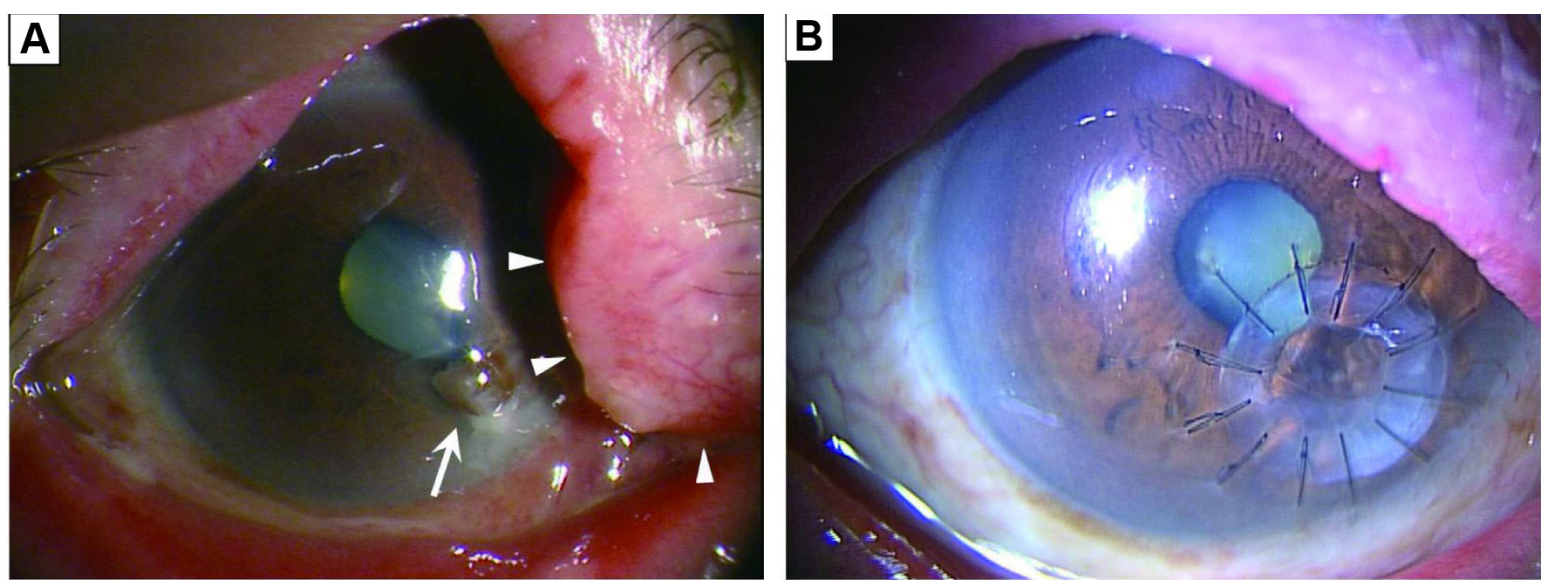

Figure 3 Representative slit-lamp biomicroscopic photograph of a noninfectious corneal perforation treated by a small patch graft.

Notes: (A) An 83-year-old man with a corneal perforation associated with canaliculitis. The iris prolapse (arrow), the shallow anterior chamber, and swelling on the superior canaliculus (arrowheads) are shown. Anaerobic bacteria (Peptostreptococcus, Prevotella, and Porphyromonas spp.) were detected by culture of the concretions in the canaliculus. (B) One year after a peripheral anterior lamellar patch graft with removal of the concretions in the canaliculus. The postoperative best corrected visual acuity was $20 / 200$. 

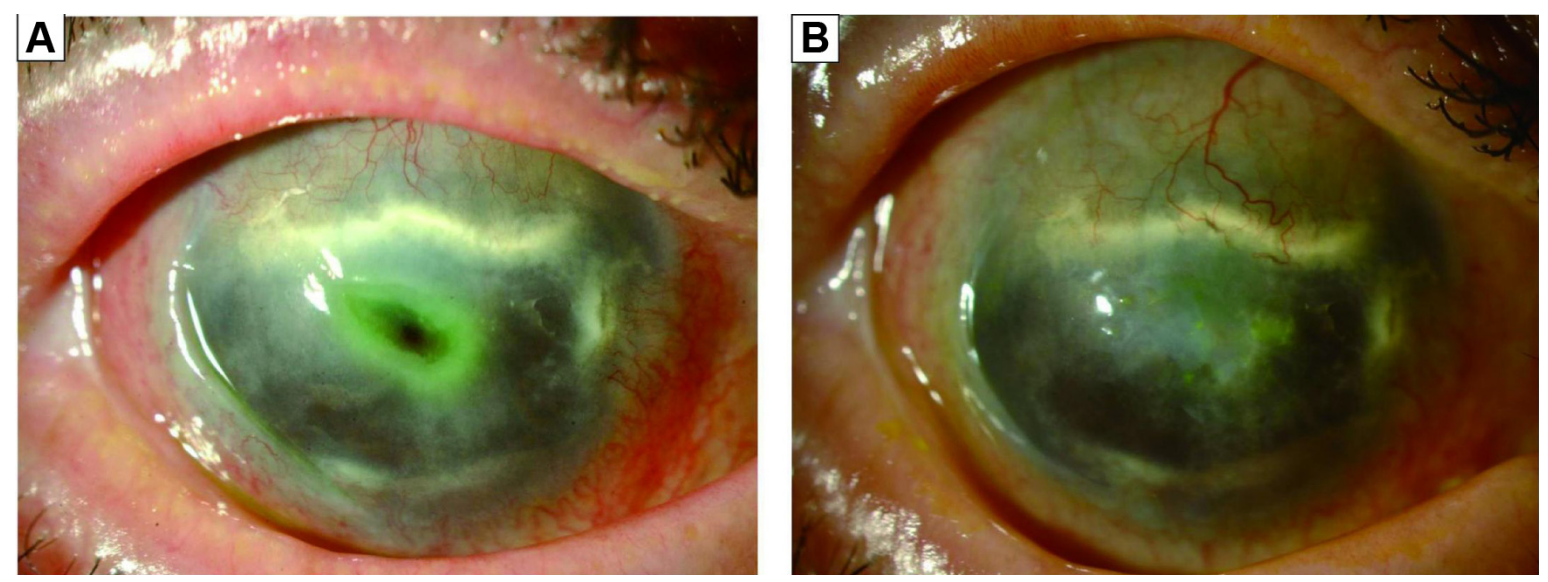

Figure 4 Representative slit-lamp biomicroscopic photograph of a noninfectious corneal perforation treated by amniotic membrane transplantation.

Notes: (A) A 70-year-old man with a corneal perforation associated with severe dry eye of mucous membrane pemphigoid. A paracentral small perforation was noted in the corneal ulcer with a positive Seidel test. Inflamed conjunctiva, corneal pannus, and symblepharon were noted. (B) One year after treatment with cryopreserved human amniotic membrane with punctal occlusion. The ocular surface was re-epithelialized and the best corrected visual acuity was equal to the preoperative level (counting fingers).

In all cases, anatomic cure was ultimately obtained. Among 31 cases, 28 cases had follow-up longer than 6 months (mean, $26.9 \pm 20.6$ months) after repair surgery. However, three of 17 central large grafts $(20 \%)$ became cloudy due to conjunctivalization $(n=1)$, endothelial failure $(n=1)$, or recurrent herpetic stromal keratitis $(n=1)$. Data on preoperative and 6 months postoperative best corrected visual acuity (BCVA) were available in 25 cases. Mean postoperative BCVA after 6 months (logMAR 1.3) was better than that of preoperative levels (logMAR 1.8) ( $P=0.0018$, paired Student's $t$-test) (Figure 5). Secondary glaucoma developed in eight eyes (21.4\%) within 6 months. Although these eight eyes required medical intervention, antiglaucoma surgery was not performed.

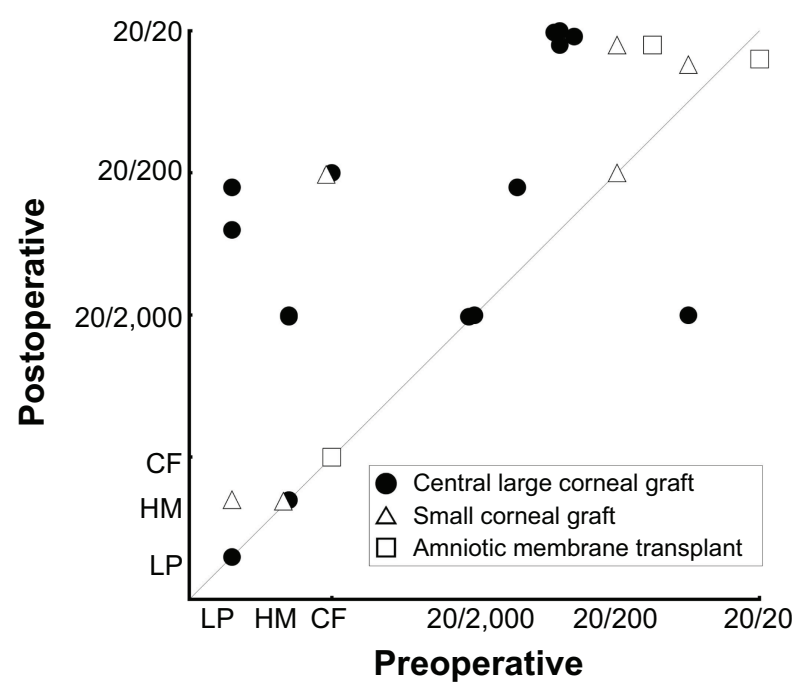

Figure $\mathbf{5}$ Visual outcomes of 25 cases that were followed for longer than 6 months after corneal perforation repair.

Abbreviations: CF, counting fingers; HM, hand motions; LP, light perception.

\section{Discussion}

Herein, we analyzed 31 eyes of 31 patients with surgically treated corneal perforations during the past decade in a tertiary referral hospital in Japan. As a result, the trend of surgical options and efficacy of those procedures are clearly presented. Table 3 shows our recent policy for the choice of surgical procedure as determined by cause, location, and size of corneal perforation.

We surgically managed 8 cases of corneal perforation due to infectious keratitis. Seven cases were successfully treated by a central large corneal graft on the first attempt. However, one case with fungal ulcer was not cured by a small patch graft due to the recurrence of the lesion. A central large graft was subsequently required. The success rate of therapeutic keratoplasty for infectious keratitis is influenced by many factors, including microbial organism virulence, predisposing factors, extensiveness of pre-existing keratitis, associated ocular surface inflammation, initial medical treatment, and surgical techniques. ${ }^{5}$ One of the serious problems in therapeutic keratoplasty for fungal ulcer is postoperative recurrence of the fungal infection, although penetrating keratoplasty is an effective approach to remove fungal organisms for medically uncontrolled fungal ulcers. Ti et $\mathrm{al}^{5}$ analyzed 92 cases of therapeutic keratoplasty for acute infectious keratitis in Singapore. There were 15 therapeutic failures (finally evisceration or phthisis), of which 11 were the result of fungal keratitis. Li et $\mathrm{al}^{6}$ reported 116 cases of fungal keratitis treated with therapeutic keratoplasty. Thirteen cases $(11.2 \%)$ had a recurring fungal infection and in 112 cases $(96.6 \%)$ the eyeball was preserved. When fungal infection extends to the limbal area, the extensive disease 
Table 3 Our recommended policy for surgical procedures of corneal perforations

\begin{tabular}{|c|c|c|c|}
\hline \multirow[t]{2}{*}{ Causes } & \multirow[t]{2}{*}{ Location } & \multicolumn{2}{|l|}{ Size } \\
\hline & & Larger than $1.5 \mathrm{~mm}$ in diameter & $\begin{array}{l}\text { Smaller than } 1.5 \mathrm{~mm} \\
\text { in diameter }\end{array}$ \\
\hline Infectious keratopathy & $\begin{array}{l}\text { Anywhere (peripheral } \\
\text { localization is rare) }\end{array}$ & Large penetrating corneal graft & $\begin{array}{l}\text { Large penetrating } \\
\text { corneal graft }\end{array}$ \\
\hline \multirow[t]{3}{*}{ Noninfectious keratopathy } & Central & $\begin{array}{l}\text { Large penetrating (or lamellar) } \\
\text { corneal graft }\end{array}$ & $\begin{array}{l}\text { Large penetrating (or } \\
\text { lamellar) corneal graft }\end{array}$ \\
\hline & Paracentral & $\begin{array}{l}\text { Large penetrating (or lamellar) } \\
\text { corneal graft }\end{array}$ & $\begin{array}{l}\text { Amniotic membrane } \\
\text { transplant }\end{array}$ \\
\hline & Peripheral & $\begin{array}{l}\text { Small circular or crescentic lamellar } \\
\text { (or penetrating) corneal graft }\end{array}$ & $\begin{array}{l}\text { Amniotic membrane } \\
\text { transplant }\end{array}$ \\
\hline
\end{tabular}

may require sclerokeratoplasty or evisceration. The most common fungal organisms isolated preceding and during therapeutic keratoplasty include Fusarium, Aspergillus, and Candida ${ }^{5,6}$ Only the Candida species was detected in our four cases with fungal ulcers.

There are a variety of surgical options for noninfectious corneal perforations. For relatively large-sized perforations (larger than approximately $1.5 \mathrm{~mm}$ in diameter), we performed corneal transplantation in the form of lamellar $(n=7)$ or penetrating $(n=10)$ keratoplasty. Anterior lamellar keratoplasty has the advantages of reduction of allograft endothelial rejection and secondary glaucoma, compared to penetrating keratoplasty. However, postoperative BCVA is limited by graft-host interface haze in central large anterior lamellar keratoplasty. Peripheral small-size lamellar keratoplasty should be considered for peripheral noninfectious corneal perforation, as postoperative graft-host interface haze or sutures will not interfere with the visual axis (Figure 3 ). A full-thickness small patch graft may be as effective as a small lamellar graft and is technically easier to perform. Although technically demanding, deep anterior lamellar keratoplasty with removal of the host tissue down to the Descemet's membrane for corneal perforations may reduce graft-host interface haze and have a better visual prognosis. ${ }^{7}$ Recent development of high-resolution anteriorsegment optical coherence tomography allows the measurement of microscopic structures of the anterior segment, such as corneal thickness map. Anterior-segment optical coherence tomography may be a useful tool for making decisions about performing anterior lamellar keratoplasty and lamellar dissection design.

As reported previously by Rodríguez-Ares et $\mathrm{al}^{4}$ multilayered AMT was confirmed in this study to be quite effective for small-size noninfectious perforations. Two advantages of multilayered AMT for corneal perforations are that amniotic membrane has no antigenicity (and therefore there will be no rejection) and causes less astigmatism compared to a peripheral corneal patch graft. Also, AMT is readily available in the form of both cryopreserved and freeze-dried preservation. Furthermore, AMT has numerous beneficial properties for ocular surface diseases, including mechanical protection, re-epithelialization, and reduction of inflammation. 3,4,11,12

In this study, mean postoperative BCVA was better than that of preoperative levels. BCVA after repair surgery was sometimes influenced by cataract progression associated with severe inflammation and corticosteroids use. In our 25 cases of phakic eyes, four eyes underwent simultaneous cataract surgery with penetrating keratoplasty and five eyes underwent secondary cataract surgery after repair surgery. Simultaneous or secondary cataract surgery must be selected on a case-by-case basis, taking into consideration the benefitrisk ratio.

In this study, we experienced two interesting cases with corneal perforation caused by canaliculitis. In both cases, anaerobic bacteria were detected from cultures of concretion of the canaliculus. Allergies against toxins produced by some bacteria are thought to be involved in the mechanism underlying corneal perforations associated with canaliculitis or dacryocystitis. ${ }^{13,14}$ One case was successfully cured by peripheral anterior lamellar keratoplasty with removal of the concretions of the canaliculus (Figure 3), and the other case was successfully cured by multilayered AMT with removal of the concretions of the canaliculus. Appropriate diagnosis and treatment of the lacrimal drainage system are recommended for better postoperative prognosis.

Most notably, we report for the first time a case of corneal perforation associated with the anticancer drug S-1. We were unable to find any previous reports about corneal perforations associated with S-1 in a PubMed database search performed in April 2014. S-1 consists of the 5-fluorouracil prodrug tegafur, 5-chloro-2,4-dihydroxypyridine, and potassium oxonate. S-1 is used in Japan for the treatment of advanced 
gastric, colon, pancreatic, and lung cancer. In the ophthalmologic field, keratopathy and canalicular obstruction are well known side effects of S-1. ${ }^{15-17}$ In our case, persistent epithelial defect developed into a sterile ulcer and resulted in corneal melting. Continuous wear of bandage soft contact lenses and reduction of S-1 intake may be recommended for cases with severe keratoepitheliopathy associated with S-1. As well as S-1 keratoepitheliopathy, in our lagophthalmos and dry-eye cases, persistent epithelial defects developed into sterile ulcers and resulted in corneal perforation. After removal of a metal foreign body, proteases secreted from white cells around the rust rings could cause corneal melting.

\section{Conclusion}

Surgical therapies for corneal perforations in our tertiary referral hospital include central large lamellar/penetrating keratoplasty, small peripheral patch graft, and multilayered AMT. All of these treatments were effective. Corneal perforation due to the oral anticancer drug S-1 is reported for the first time. The optimal surgical procedure should be selected by cause, size, and location of the corneal perforation.

\section{Acknowledgment}

This study was supported by a Grant-in-Aid for Scientific Research (KAKENHI), Japan (No. 25462705).

\section{Disclosure}

No authors have any financial/conflicting interests to disclose. The corresponding investigator (HY) had full access to all of the data in the study and takes responsibility for the integrity of the data and accuracy of the data analysis. The authors report no other conflicts of interest in this work.

\section{References}

1. Jhanji V, Young AL, Mehta JS, Sharma N, Agarwal T, Vajpayee RB. Management of corneal perforation. Surv Ophthalmol. 2011;56(6): 522-538.

2. Kobayashi A, Yokogawa H, Sugiyama K. Management of a small paracentral corneal perforation using iatrogenic iris incarceration and tissue adhesive. Case Rep Ophthalmol. 2012;3(2):226-229.

Clinical Ophthalmology

\section{Publish your work in this journal}

Clinical Ophthalmology is an international, peer-reviewed journal covering all subspecialties within ophthalmology. Key topics include: Optometry; Visual science; Pharmacology and drug therapy in eye diseases; Basic Sciences; Primary and Secondary eye care; Patient Safety and Quality of Care Improvements. This journal is indexed on Submit your manuscript here: http://www.dovepress.com/clinical-ophthalmology-journal
3. Hanada K, Shimazaki J, Shimmura S, Tsubota K. Multilayered amniotic membrane transplantation for severe ulceration of the cornea and sclera. Am J Ophthalmol. 2001;131(3):324-331.

4. Rodríguez-Ares MT, Touriño R, López-Valladares MJ, Gude F. Multilayer amniotic membrane transplantation in the treatment of corneal perforations. Cornea. 2004;23(6):577-583.

5. Ti SE, Scott JA, Janardhanan P, Tan DT. Therapeutic keratoplasty for advanced suppurative keratitis. Am J Ophthalmol. 2007;143(5): 755-762.

6. LiC, Zhao GQ, Che CY, et al. Effect of corneal graft diameter on therapeutic penetrating keratoplasty for fungal keratitis. Int J Ophthalmol. 2012; 5(6):698-703.

7. Shimmura S, Shimazaki J, Tsubota K. Therapeutic deep lamellar keratoplasty for cornea perforation. Am J Ophthalmol. 2003; 135(6):896-897.

8. Hanada K, Igarashi S, Muramatsu O, Yoshida A. Therapeutic keratoplasty for corneal perforation: clinical results and complications. Cornea. 2008;27(2):156-160.

9. Lange C, Feltgen N, Junker B, Schulze-Bonsel K, Bach M. Resolving the clinical acuity categories "hand motion" and "counting fingers" using the Freiburg Visual Acuity Test (FrACT). Graefes Arch Clin Exp Ophthalmol. 2009;247(1):137-142.

10. Grover S, Fishman GA, Anderson RJ, et al. Visual acuity impairment in patients with retinitis pigmentosa at age 45 years or older. Ophthalmology. 1999;106(9):1780-1785.

11. Tseng SC, Li DQ, Ma X. Suppression of transforming growth factor-beta isoforms, TGF-beta receptor type II, and myofibroblast differentiation in cultured human corneal and limbal fibroblasts by amniotic membrane matrix. J Cell Physiol. 1999;179(3):325-335.

12. Kobayashi A, Yoshita T, Sugiyama K, et al. Amniotic membrane transplantation in acute phase of toxic epidermal necrolysis with severe corneal involvement. Ophthalmology. 2006;113(1):126-132.

13. Takeda H, Okamura S, Mizobe Y, et al. A case of marginal corneal ulcer with lacrimal canaliculitis due to anaerobic bacteria. Japanese Review of Clinical Ophthalmology. 2007;101:759-761.

14. Komatsu K, Nakaso N, Miyazaki D, Inoue Y. A case of rheumatoid corneal perforation associated with dacryocystitis. Folia Ophthal Jap. 2005;56(9):760-764.

15. Chikama T, Takahashi N, Wakuta M, Nishida T. Noninvasive direct detection of ocular mucositis by in vivo confocal microscopy in patients treated with S-1. Mol Vis. 2009;15:2896-2904.

16. Kobashi H, Kamiya K, Shimizu K. A case of corneal epithelial lesion and keratoconjunctival pigmentation due to anticancer drug S-1.Jpn J Ophthalmol. 2011;55(2):163-165.

17. Sasaki T, Miyashita H, Miyanaga T, Yamamoto K, Sugiyama K. Dacryoendoscopic observation and incidence of canalicular obstruction/ stenosis associated with S-1, an oral anticancer drug. Jpn J Ophthalmol. 2012;56(3):214-218.

\section{Dovepress}

PubMed Central and CAS, and is the official journal of The Society of Clinical Ophthalmology (SCO). The manuscript management system is completely online and includes a very quick and fair peer-review system, which is all easy to use. Visit http://www.dovepress.com/ testimonials.php to read real quotes from published authors. 